\title{
Agluonos šventovės istorinės kilmės priežastys
}

\author{
ALFONSAS MOTUZAS \\ Lietuvos edukologijos universitetas, T. Ševčenkos g. 31, LT-03111 Vilnius \\ El. paštas: a.motuzas@ktf.vdu.lt
}

\begin{abstract}
Straipsnyje tiriamos Agluonos šventovès Latvijoje istorinès kilmès priežastys kaip katalikiško tikèjimo Šiaurès rytų Europoje stiprinimo, kovų už tikèjimo laisvę išdavos rezultatas arba katalikiškos Europos priešakinė pozicija prieš stačiatikybę ir protestantizmą.
\end{abstract}

Raktažodžiai: istorija, Latvija, Agluona, šventovė

\section{IVADAS}

Rytinejje Latvijos dalyje Latgaloje yra Agluonos Bazilika, tarptautinės reikšmès katalikų piligrimų vieta, kurią 1993 m. rugsèjo 9 d. aplankè popiežius Jonas Paulius II. Agluonos papuošalas - Baltieji Dievo namai, kuriuos sudaro bažnyčia, vienuolynas, Šv. Antano šaltinis ir šventoriaus tvoros 6-ių vartų nišose įtaisytos Jėzaus Kristaus kančios kelio skulptūros, vadinamos 14-os stočių Kryžiaus keliu.

Agluona - tai katalikiškos Latvijos ir Šiaurès rytų Europos perlas, ypač suspindintis Švč. Dievo Motinos Marijos Dangun Émimo atlaidų oktavos (rugpjūčio 7-16 d.) šventès metu, kada meldžiamasi prie Švč. Dievo Motinos Marijos Dangun Ėmimo malones teikiančio paveikslo, prieš ar po šventų mišių prie Trijų Kryžių monumento bei apvaikštant bažnyčios šventoriaus Kryžiaus kelio stotis, arba mažąsias kalvarijas. Apie Agluonos šventovès istoriją yra paskelbta medžiagos: $1856 \mathrm{~m}$. apie tai rašẻ lenkų mokslininkas Dominikas Chodżko monografijoje Kościól i klasztor OO Domininkanow [6], išsamiai apie tai rašyta $1991 \mathrm{~m}$. latvių mokslininko Franco Kemps knygoje Latgales likten,i [7], 1993 m. publikacijoje „Aglonas Bazilika“, kuri paskelbta leidinyje Katōlu Dzeive [2], 1994 m. Bonifacijaus Briškos studijoje Latgola muna tāvzeme [4] bei 1998 m. Ingos Pettere studijoje Daugavpils Novada. Krucifiksi [11]. Apie šį fenomeną 1999 m. rašè kun. Robertas Skrinskas knygoje Piligrimo vadovas po stebuklingas Marijos vietas [13], Viktoras Perkūnas monografijoje Dominikonai Lietuvos kultūroje [10] bei šio straipsnio autorius 2006 m. publikacijoje „Кулът горы трёх крестов в Аглоне (Латвия), Вильнюсе (Литва) и Казимиерц Дольни (Польша)“ [16, 321-322].

Pastaruoju metu apie Agluonos šventovès kilmès priežastis internetinejje spaudoje pasirodè naujų įžvalgų, su kuriomis šio straipsnio autorius nesutinka, todèl ir iškilo klausimas, kas paskatino šios šventovès susiformavimą? Tyrimo objektas - Agluonos šventovè, tyrimo tikslas - atskleisti Agluonos šventovės atsiradimo kilmès priežastis. Tyrimo tikslui pasiekti 
buvo iškelti šie uždaviniai: pirma, ištirti ir pateikti spausdintą ir internetinę medžiagą apie Agluonos šventovę šiuo klausimu; antra, remiantis Lenkijos, Lietuvos ir Latvijos istorijų bei Katalikų Bažnyčios istorijos šaltiniais, atskleisti naujas įžvalgas apie šios šventovès kilmès priežastis bei trečia - pateikti išvadas. Tyrimo metodai - aprašomasis, analitinis ir sintezès.

Ši tema yra aktuali nūdienos Latvijos ir Lietuvos Katalikų Bažnyčių kultūros istorijos mokslui.

\section{IŠ AGLUONOS ŠVENTOVĖS ISTORIJOS}

Apie šios šventovès istoriją yra paskelbta daug rašytinès medžiagos, kuri glaustai ir išsamiai pristatoma ịvairiomis pasaulio kalbomis kompaktinèje plokštelèje „Basilica Aglonensis“. Teigiama, kad Agluonos šventovès istorija prasideda XVII a. pabaigoje, kada Viškovos (dabartinès Agluonos) dvaro savininke Eva Justine Šostovicka, remiama Livonijos vyskupo Mikalojaus Poplavskio, 1697 m. pakvietè vienuolius dominikonus iš Vilniaus ịkurti vienuolyną ir parapijos mokyklą. Atvykę vienuoliai ilgai neradę vietos, kur statyti vienuolyną. Legenda sako, kad tuo metu pas garbingąją dvarininkę gyveno latvių našlaitė vardu Anna, kuriai rugpjūčio 15 dieną vienai besimeldžiant tankiame eglyne tarp dviejų eglių pasirodè Dievo Motina su vaikeliu ant dešinès rankos, o tuo pačiu metu dominikonų vienuoliui T. Remigijui - baltos bažnyčios su aukštais bokštais vizija. Tankiame eglyne, kur tarp dviejų eglių pasirodè Dievo Motina, $1699 \mathrm{~m}$. buvo pastatytas vienuolynas, o $1700 \mathrm{~m}$. - pirmoji medinẻ bažnyčia. Iš čia ir kilo šventovès pavadinimas Aglenia (latviškai - aut. past.), dabar Agluona. Netrukus Vilniaus vienuoliai dominikonai bažnyčios centriniame altoriuje įtaisė Trakų Dievo Motinos paveikslo kopiją, kurios originalą $1718 \mathrm{~m}$. rugsẻjo $8 \mathrm{~d}$. vainikavo Vilniaus vyskupas Kazimieras Konstantinas Brzostovskis [1, 56]. 1751 m. bažnyčiai buvo suteiktas Švč. Mergelès Marijos Ėmimo ị dangų vardas ir patvirtinta ši šventė. 1780 m. sudegus Agluonoje medinei bažnyčiai, buvo pastatyta nauja mūrinė, vienuolynas bei šventoriaus tvora su 6 vartais, kurių nišose buvo įstatytos Jėzaus Kristaus kančios kelio skulptūros, vadinamos mažosiomis kalvarijomis, arba 14-os stočių Kryžiaus keliu. Agluona tapo viena iš paskutinių katalikiškų šventovių (toliau ị rytus buvo Rezeknė - aut. past.) Šiaurès rytų Europoje. Agluonos šventovę supa ežerai, o rytinèje pusėje - stebuklingas šaltinis, kuris nuo $1824 \mathrm{~m}$. dèl savo gydomųjų savybių pavadintas Šv. Antano šaltiniu [3].

Pažvelkime, kokia medžiaga apie Agluonos šventovès kilmę lietuvių kalba pateikiama internete. Čia rašoma, kad šią vietą bažnyčios statybai krikščionių misionieriai parinko neatsitiktinai - buvo bent dvi priežastys. Pirma, senoveje čia buvo aukojimų šventvietè - greta Egles ežero tryško gydomojo vandens šaltinèlis, augo šventais laikyti ąžuolai ir eglès. Antra - žinomas liudijimas apie Lietuvos karaliaus Mindaugo kapavietę Agluonoje datuojamas 1618 m., kada protestantų pastorius rado juodo marmuro antkapinę plokštę, patvirtinančią karaliaus Mindaugo kapą. Manoma, kad čia jis buvo nužudytas 1263 m. rugsėjo 12-ąją. O jau $1697 \mathrm{~m}$. ịtakinga Agluonos žemvaldè Eva Justine Selicka-Szostowicki iš Lietuvos pasikvietė dominikonų ordiną ir paprašė čia pastatyti medinę bažnyčią ir vienuolyną, kad regione sustiprintų katalikybę ir kartu pagerbtų vienintelio Lietuvos karaliaus Mindaugo atminimą [18]. Pabandykime paprieštarauti kažkuriems samprotavimams argumentuodami šiais duomenimis.

\section{AGLUONOS ŠVENTOVĖS KILMĖS IŠTAKŲ PRIEŽASTYS}

Apie Agluonos šventovės kilmę internete skelbiama pirmoji versija, kad šią vietą bažnyčios statybai krikščionių misionieriai, t. y. pakviestieji iš Vilniaus dominikonai, parinko neatsitiktinai, o siekdami pakeisti senovèje čia buvusią aukojimų šventvietę, yra nepriimtina. 
Agluonoje šventovė pastatyta XVII-XVIII amžių sandūroje, kai krikščionybė jau buvo tvirtai įsigalejusi Latvijoje. Krikščionybės ištakos Latvijoje siekia XII a. pabaigą (1186 m.). Nuo 1212 m. Laterano Susirinkimas suteike Livonijai (dabartiniai Latvijos ir Estijos teritorijų plotai - aut. past.) vardą Terra Mariana, o Rygos miesto globejja paskyrè Švč. Mergelę Mariją $[8,3]$. Taip Latvija tapo katalikišku kraštu.

1561 m. Latgala prijungta prie Lietuvos Didžiosios Kunigaikštystès, o po 1569 m. Liublino unijos akto, kai Lietuvos Didžioji Kunigaikštystė susijungė su Lenkijos karalyste ị Abiejų Tautų Respubliką (Rzeczpospolita Obojga Narodów, toliau - Respublika - aut. past.), i Livonijos Latgalos žemę pakviečiami naujakuriai (bajorai) iš Lenkijos (polskie inflianty).

1600 m. prasidejo pirmasis Respublikos karas su Švedija, kurio viena iš priežasčių buvo reformacijos ir kontrreformacijos sąjūdis Europoje. Karas baigèsi 1629 m. Altmarko paliaubomis. Švedijai atiteko užgrobtosios Pietų Estija ir visa Vakarų bei Pietvakarių Latvija su Rygos miestu, o Respublikai liko Pietų Latvija (Latgala), pavadinta Inflianty Polskie, kad būtų galima skirti nuo Švedijos Infliantų. Šis padalijimas nulèmè protestantizmo ịsigalèjimą didesnèje Latvijos dalyje, o Latgaloje - katalikybės. Matyt, todèl Agluonoje i̊sikuria ir iš Lenkijos atvykę naujakuriai dvarininkai Šostovickiai (tą dar reikètų patyrinèti - aut. past.).

Su antrąja internetine versija, pasak kurios, dvarininkai Šostovickiai pakvietė dominikonus vienuolius iš Vilniaus, kad jie ne tik pastatytų bažnyčią, vienuolyną, bet ir sustiprintų regione katalikybę ir kartu pagerbtų vienintelio Lietuvos karaliaus Mindaugo atminimą, galima sutikti tik iš dalies. Vargu, ar lenkų dvarininkams rūpejjo legendomis apipintas vienintelio Lietuvos karaliaus Mindaugo žūties vietos įamžinimas.

O dèl katalikybès tvirtesnio įsitvirtinimo Latgaloje tenka sutikti. Tam, matyt, turèjo įtakos Respublikos (ị kurią ịejjo ir Latgala) Katalikų Bažnyčios ir lenkų bajorijos nuojauta apie artėjančią grèsmę iš rytų. Tam tikslui, matyt, ir buvo ị Agluoną pakviesti ir ịkurdinti vienuoliai dominikonai iš Vilniaus (1698-1700), kurie kaip priešpriešą artėjančiai stačiatikybei i̊steigè Lietuvoje malonėmis garsẻjančio seniausio Trakų Dievo Motinos paveikslo kopijos pamaldumą. Kaip teigia rašytiniai šaltiniai, pats Trakų Dievo Motinos paveikslo originalas, kraštą palietus nelaimėms, garsėjo teikiančiomis malonėmis $[14,282]$. To ir buvo tikimasi iš jos kopijos.

Kyla klausimas, kodèl misijoms buvo pasirinkti vienuoliai dominikonai? Galbūt todèl, kad vienas iš šio ordino reikalavimų - mokytumas. Jie vadovavo intelektualiam krikščionybės gyvenimui, steigè mokyklas, dèstė teologiją ir filosofiją, kaip misijonieriai keliavo po visą pasauli. $1647 \mathrm{~m}$. Abiejų Tautų Respublikoje buvo sudaryta atskira Lietuvos dominikonų provincija [5, 456], kuri tikriausiai ir buvo atsakinga už misijas Latgaloje (Latvija).

1700 m. prasidejjęs karas su Rusija (vad. Šiaurès karas) truko 21 metus ir baigèsi tuo, kad Estija ir visa Latvija su Ryga (išskyrus Latgalą) buvo prijungtos prie Rusijos imperijos.

Karo metu Abiejų Tautų Respublikos maldininkai ne kartą kreipèsi tiek ị Trakų Dievo Motinos stebuklingojo paveikslo originalą, tiek ir kopiją Agluonoje. 1718 m. Vatikanas vainikais apvainikavo Trakų Dievo Motinos paveikslo originalą, o $1751 \mathrm{~m}$. Agluonos bažnyčiai suteikè Švč. Mergelès Marijos Ėmimo ị dangų titulą ir ịtvirtino šio titulo šventę tuo parodydamas kaimyninems protestantiškoms ir stačiatikiškoms šalims Latgalos krašto Marijos Žemés titulo tvirtybę bei Vatikano tarpusavio ryšius su Latvija, Lietuva ir Lenkija. Šio paveikslo originalo ir kopijos pagerbimas pažymėtinas dar todèl, kad iki tol LietuvojeLenkijoje $1717 \mathrm{~m}$. buvo vainikuotas tik vienas Čenstakavos paveikslas. Yra žinoma, kad apie 1800 m. buvęs Agluonos vienuolyno auklètinis Dombrovskis Agluonos Dievo Motinos 
paveikslą papuošè sidabriniu paauksuotu aptaisu, spinduliais ir karūna su brangakmeniais $[13,374]$.

Latgalos (Latvijos), Lietuvos ir Lenkijos valstybių vienybė truko iki $1772 \mathrm{~m}$. rugpjūčio 5 d., pirmojo Respublikos padalijimo, kai Rusija, Austrija ir Prūsija pasidalijo Latvijos, Lietuvos ir Lenkijos žemes bei pripažino lygias teises kitatikiams. Tai buvo nauja grèsmè katalikybei. Matyt, tam tikslui $1780 \mathrm{~m}$. buvo pastatyta nauja mūrinė bažnyčia, vienuolynas bei šventoriaus tvora su kryžiumi, Trijų Kryžių kalno monumentu ir 6 vartais, kurių nišose isstatytos Jėzaus Kristaus kančios kelio skulptūros. Taip buvo ịkurta 14-os stočių Kryžiaus kelio, arba mažųjų kalvarijų, pamaldumo praktika, o Agluonos šventovės šventoriaus tvora ir 14-os stočių Kryžiaus kelias tapo tikejjimo gynybine, apsaugine ir pamaldumo sistema.

Netrukus įvyko 2-asis padalijimas (1793 m.), nulèmęs nepriklausomybės pabaigą, bei 3-iasis (1795 m.), kai Latviją, Lietuvą ir Lenkiją okupavo rusai [9, 421, 436, 438-440]. Rusams 1795 m. okupavus Latviją, Lietuvą ir Lenkiją, uždrausta statyti kryžius, taip pat religines procesijas bei maldininkų keliones už bažnyčios šventoriaus ribų. Agluonos šventovejje per Sekminių tridienị besilankantiems maldininkams beliko drauge susirinkti prie netoliese esančio, Egles ežero krante tekančio sieringo šaltinio, liaudies vadinamo Šv. Antano vardu. Šio šventojo vardas buvo pasirinktas neatsitiktinai. Bažnytinėse knygose rašoma, kad Šv. Antanas, be pamestų daiktų, dar yra keliautojų ir ligonių globėjas [5, 435, 437]. Taigi stebuklingasis gydomasis Šv. Antano šaltinis buvo ir maldininkų suejjimų, ir malonių gavimo vieta.

Kyla klausimas, kodèl buvo pasirinktos Sekminės? Sekminės švenčiamos tarp gegužès 11 ir birželio 12 d. (septintąji sekmadieni po Velykų) - tai Jėzaus Kristaus žadètos Šventosios Dvasios atsiuntimo apaštalams šventè. Sekminės yra paskutinė Velykų laikotarpio diena. Šventosios Dvasios atsiuntimui paminèti bažnyčioje rengiama procesija. Dalyvaudami joje mintimis susisiejame su Švč. Mergele Marija ir apaštalais, besimeldžiančiais Paskutinès vakarienès kambaryje, kur ant jų nuženge Šventoji Dvasia [12, 341]. Pats Šventosios Dvasios nusileidimas ugnies liežuvių pavidalu ant apaštalų, suteikęs jiems galią kalbèti visomis kalbomis, pranašauti, gydyti, aprašytas Apaštalų darbų knygoje [Apd 2, 1-11]. Nèra žinoma, kada Agluonoje pradètos švęsti Sekminès, bet liaudies pamaldume jos jau žinomos nuo XIX a., kada per šią šventę apvaikštomas bažnyčios šventoriuje įrengtas 14-os stočių Kryžiaus kelias [15]. Sunkiais carinès Rusijos priespaudos metais Sekminių šventė Agluonoje sukviesdavo katalikų maldininkus kartu pabūti ne tik su malda, bet ir prie Šv. Antano šaltinio, keliaujančio Katalikų Bažnyčios simbolio.

Yra žinoma, kad 1824 m. tuometiné caro valdžia leido dominikonams Sankt Peterburgo Medicinos akademijoje atlikti šio šaltinio vandens analizę. Paaiškejjo, kad šaltinio sieringas vanduo gali būti naudojamas gydymo tikslams, todèl netrukus buvo leista pastatyti 10 vietú ligoninę [17]. Ši gydykla galèjo būti vienas iš motyvų, kodèl carinei valdžiai uždarinèjant bažnyčias ir vienuolynus Agluonos šventovè išliko.

Net 124 metus šie katalikiški kraštai meldèsi ir kovojo už katalikiško tikejjimo laisvę. Ji buvo iškovota, bet po 22 metų Latviją ir Lietuvą užtemdè sovietinis ateizmas, kuris tik po Nepriklausomybès $(1991 \mathrm{~m}$.) atkūrimo pasitraukè iš Latvijos. $1993 \mathrm{~m}$. rugsèjo $9 \mathrm{~d}$. Agluonoje lankèsi popiežius Jonas Paulius II. Artejjant popiežiaus vizitui į Latviją, paskutiniajame XX a. dešimtmetyje prieš bažnyčią buvo įrengta sakrali aikštè, naudojama tiek procesijoms, tiek Kryžiaus keliui apeiti, tiek maldininkams susiburti pamaldų metu. Aikštè suformuota kaip atskira sakrali vieta, kartu su bažnyčia sudaranti bendrą ansamblị, kurị palaimino Romos popiežius Jonas Paulius II. 
Lentelè. Istoriniai j̨vykiai ir Agluonos šventovès kilmès ištakos

\begin{tabular}{|c|c|c|c|c|}
\hline Eil. Nr. & Datos & lvykiai & $\begin{array}{l}\text { Priežastys, nulèmusios } \\
\text { šventovès ịkūrimą }\end{array}$ & Versija \\
\hline \multirow[t]{3}{*}{1.} & \multirow[t]{3}{*}{$1697-1700 \mathrm{~m}}$. & \multirow{3}{*}{$\begin{array}{c}\text { l Agluoną iš Vilniaus } \\
\text { pakviečiami vienuoliai } \\
\text { dominikonai, kad pastatytų } \\
\text { vienuolyną ir bažnyčią }\end{array}$} & $\begin{array}{l}\text { 1. Ikikrikščioniškaji tikèjimą } \\
\text { pakeisti krikščioniškuoju }\end{array}$ & - \\
\hline & & & $\begin{array}{l}\text { 2. Pagerbti vienintelio } \\
\text { Lietuvos karaliaus } \\
\text { Mindaugo atminimą }\end{array}$ & - \\
\hline & & & $\begin{array}{l}\text { 3. Latgaloje sustiprinti } \\
\text { katalikybę }\end{array}$ & + \\
\hline 2. & $1700-1721 \mathrm{~m}$. & Šiaurės karas & $\begin{array}{c}\text { Vienuoliai dominikonai } \\
\text { isteigia Trakų Dievo moti- } \\
\text { nos paveikslo kopijos } \\
\text { pamaldumą kaip apsauginę } \\
\text { priemonę prieš stačiatikybę ir } \\
\text { protestantizmą }\end{array}$ & + \\
\hline 3. & $1751 \mathrm{~m}$. & $\begin{array}{c}\text { Vatikanas Agluonos bažnyčiai } \\
\text { suteikė Švč. Mergelès Marijos } \\
\text { Émimo i dangų vardą ir } \\
\text { patvirtino šio vardo šventę }\end{array}$ & $\begin{array}{l}\text { Latgaloje sustiprinti } \\
\text { katalikybę }\end{array}$ & + \\
\hline 4. & $1780 \mathrm{~m}$. & $\begin{array}{l}\text { 1-uoju Respublikos } \\
\text { padalijimu pripažistamos } \\
\text { lygios teisès kitatikiams, } \\
\text { iškyla nauja grèsmè } \\
\text { katalikybei }\end{array}$ & $\begin{array}{c}\text { Kaip stipri apsauginė } \\
\text { priemonė pastatyta nauja } \\
\text { mūrinè bažnyčia, vienuolynas } \\
\text { bei bažnyčios šventoriaus } \\
\text { tvora su } 14-\text {-os stočių Kryžiaus } \\
\text { keliu, arba mažosiomis } \\
\text { kalvarijomis }\end{array}$ & + \\
\hline \multirow[t]{2}{*}{5.} & \multirow[t]{2}{*}{$1795-1919 \mathrm{~m}}$. & \multirow{2}{*}{$\begin{array}{c}\text { 3-iuoju Respublikos } \\
\text { padalijimu Latgalą } \\
124 \text { metus okupavo rusai, } \\
\text { atimama tautinè ir } \\
\text { tikèjimo laisvè }\end{array}$} & $\begin{array}{c}\text { 1. Šv. Antano šaltinio } \\
\text { gydomuju savybių ir malonių } \\
\text { gavimo įteisinimas } 1824 \text { m. }\end{array}$ & + \\
\hline & & & $\begin{array}{l}\text { 2. Sekminių tridienio } \\
\text { šventimas }\end{array}$ & + \\
\hline
\end{tabular}

Sutartiniai ženklai: + priimtina versija; - nepriimtina versija.

\section{IŠVADOS}

Pateikta medžiaga leidžia daryti šias išvadas.

1. Agluonos šventovę sudaro bažnyčia su stebuklingu Dievo Motinos paveikslu, vienuolynas, bažnyčios šventoriaus tvora su 14-os stočių Kryžiaus keliu ir Šv. Antano šaltinis. Laikmečių îvykiai lèmè, kad iš šių objektų susiformavo vientisa Agluonos šventovė.

2. Agluonos šventovès ištakos datuojamos XVII a. pabaiga: $1697 \mathrm{~m}$. vietos dvasininkija ir bajorija pakviete vienuolius dominikonus iš Vilniaus sustiprinti Latgaloje katalikybę.

3. Katalikybę reikejjo sustiprinti dèl šių priežasčių:

a) Šiaurès karo; b) 1-ojo Respublikos padalijimo (1772 m. rugpjūčio 5 d.), kai buvo pripažintos lygios teisès kitatikiams ir iškilo nauja grèsmè katalikybei; c) 3-iojo Respublikos padalijimo, kada Latgalą 124 metus okupavo rusai, buvo atimta tautinè ir tikejjimo laisvè. 


\title{
Šaltiniai ir literatūra
}

[1] Aglyuna. Vēsturiskas pizeimes. Red. A. Novickis. Riga, 1929.

[2] Aglonas Bazilika. Katōḷ Dzeive. Sast. S. Tuliša, red. A. Aglonietis, māksl. P. Gleizdāns. Rēzekne, 1993.

[3] Basilica Aglonensis. Compact record disc. SIA Infodisk Media, 2005. ISBN 9984-9838-1-1.

[4] BRIŠKA, Bonifācijs. Latgola muna tāvzeme. P/s Latgaḷu izdevnīceiba, 1984.

[5] BULOTA, Alfonsas; BENYS, Laimutis. Šventujų gyvenimai. Kaunas, 1994.

[6] CHODŻKO, Dominik. Aglon. Kościól i klasztor OO Domininkanow. Warschawa, 1912.

[7] KEMPS, Franč. Latgales likten,i. Riga, 1991.

[8] KLEINTJENS, Janis. Fontes Historiae Latviae Societatis Jesu. T. II. Riga, 1941.

[9] Lietuvos istorija. Red. A. Šapoka. Vilnius, 1989.

[10] PETKUS, Viktoras. Dominikonai Lietuvos kultūroje. Vilnius: „Petro ofsetas“, 2004.

[11] PETTERE, Inga. Daugavpils Novada. Krucifiksi. Daugavpils: Latgales pētniecības institūta izdevniecība, 1998.

[12] Religijotyros žodynas. Sud. A. Petraitis. Vilnius, 1991.

[13] SKRINSKAS, Robertas. Piligrimo vadovas po stebuklingas Marijos vietas. Kaunas: „Judex“, 1999.

[14] VAIŠNORA, Juozas. Marijos garbinimas Lietuvoje. Roma, 1958.

[15] 1992-2003 m. vasaros ekspedicijų medžiaga. Kretinga: Vytauto Didžiojo universiteto Katalikų teologijos fakulteto Šv. Antano religijos studijų instituto archyvas, metai?

[16] МОТУЗАС, Альфонсас. Кулът горы трёх крестов в Аглоне (Латвия), Вильнюсе (Литва) и Казимиерц Дольни (Польша). In: Literatūra un kultūra: process, mijiedarbība, problemas. Zinātnisko rakstu kraājums VIII. Daugavpils: Saule, 2006, p. 319-335.

Prieiga per internetą:

http://www.latvia.travel/lt/agluona-ir-agluonos bazilika (žiūrèta 201212 12).

http://www.way2latvia.com/lt/keliones-latvia/agluona (žiūrèta 201207 11); http://www.latvia.travel/ lt/agluona-ir-agluonos bazilika (žiūrèta 201207 12); http://alkas.lt/2012/04/07/latvijoje-iskils-paminklas-mindaugui/ (žiūrèta 201207 12); (http://www.diena.lt/dienrastis/tema/karaliui-mindaugui-paminklas-iskils-ir-latvijoje-342688/psl-1\#ixzz213onKBV2 (žiūrèta 201207 12); (http://mapyyourinfo.com/wiki/lt.wikipedia.org/Agluona\%20(Latvija)/ (žiūrèta 201207 12).

\section{ALFONSAS MOTUZAS}

\section{Historical reasons for genesis of the Aglona Temple}

\author{
Summary
}

Aglona is an obelisk of the Catholic faith in North-Eastern Europe.

Aglona is a temple of Catholic Latvia and North-Eastern Europe that especially manifests its shine during the feast of the Assumption Octave (7-16 October) when people pray at the picture providing graces of Assumption as well as visit the Stations of the Cross (also called Calvary Stations Minor) at the churchyard before or following Holly Service. Numerous materials have been publicised regarding the history of Aglona temple. Yet new insights have been publicised on the internet recently regarding the reasons for genesis of the Aglona temple that contradict with the opinion of 
the author of the present article. Therefore, the author of this article has raised a question what reasons have predetermined formation of the said temple. In order to answer this question, the Aglona temple was selected as the object of the research. The goal raised for the present research is to disclose the reasons for genesis of the Aglona temple. The following objectives were raised in order to achieve the goals of the research: firstly, to determine and publicise what can be found regarding this issue in printed and internet-based materials; secondly, to disclose new insights on the reasons of the genesis of the said temple on the basis of Lithuanian and Latvian historic sources and resources regarding the history of the Catholic Church; thirdly, to provide conclusions based on the research carried out.

The research carried out allows making the following conclusions: 1) The Aglona temple consists of a church containing a miraculous picture of Mother of God, a monastery, a fence surrounding the churchyard and containing 14 Stations of the Cross, and the Spring of St. Anthony. Due to geopolitical events of different times, genesis of the said objects predetermined formation of an integral temple of Aglona.

2) The headwaters of the Aglona temple belong to the late 17th century, when the local clergy and gentry invited Jacobin monks from Vilnius in 1697 to strengthen Catholicism in Latgale.

3) Catholicism had to be strengthened due to the following reasons:

a) the Northern War;

b) the First Partition of the Polish-Lithuanian Commonwealth (5 October 1772) that ensured equal rights to people of other faiths and raised threat to Catholicism;

c) the Third Partition of the Polish-Lithuanian Commonwealth following which the region of Latgale was occupied by Russia for 124 years, and national as well as religious freedom was taken away.

The conclusions provide ground to the presumption presented at the beginning of the article stating that the reasons for genesis of the Aglona temple is a result of strengthening Catholic faith in North-Eastern Europe and fight for freedom of faith, or an antipode to Protestantism and Orthodoxy in Catholic Europe.

Key words: history, Lithuania, Aglona, temple 